
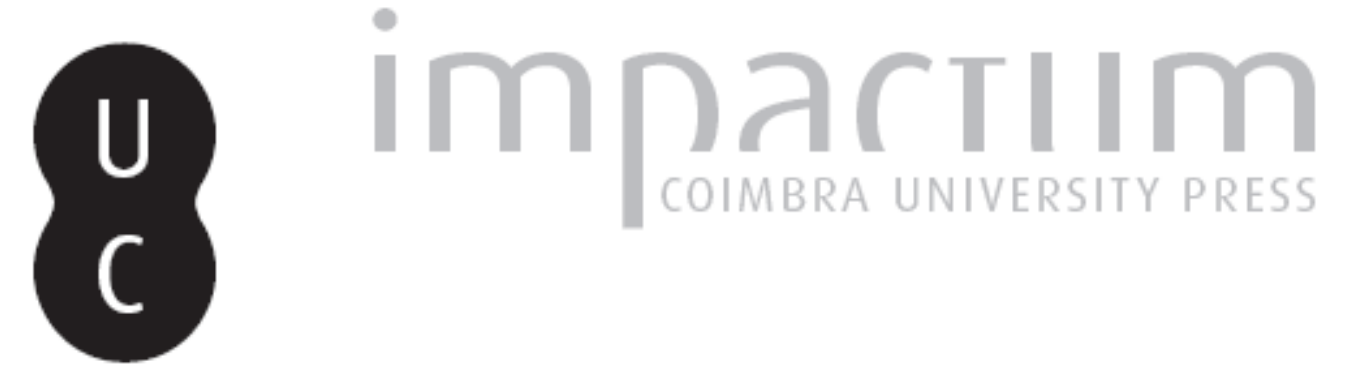

Marco António, o orador: carreira pública e oratória

Autor(es): $\quad$ Valério, João Paulo Simões

Publicado por: Centro de História da Universidade de Lisboa

URL persistente:

URI:http://hdl.handle.net/10316.2/41149

DOI:

DOI:https://doi.org/10.14195/0871-9527_25_3

Accessed : $\quad$ 26-Apr-2023 03:45:28

A navegação consulta e descarregamento dos títulos inseridos nas Bibliotecas Digitais UC Digitalis, UC Pombalina e UC Impactum, pressupõem a aceitação plena e sem reservas dos Termos e Condições de Uso destas Bibliotecas Digitais, disponíveis em https://digitalis.uc.pt/pt-pt/termos.

Conforme exposto nos referidos Termos e Condições de Uso, o descarregamento de títulos de acesso restrito requer uma licença válida de autorização devendo o utilizador aceder ao(s) documento(s) a partir de um endereço de IP da instituição detentora da supramencionada licença.

Ao utilizador é apenas permitido o descarregamento para uso pessoal, pelo que o emprego do(s) título(s) descarregado(s) para outro fim, designadamente comercial, carece de autorização do respetivo autor ou editor da obra.

Na medida em que todas as obras da UC Digitalis se encontram protegidas pelo Código do Direito de Autor e Direitos Conexos e demais legislação aplicável, toda a cópia, parcial ou total, deste documento, nos casos em que é legalmente admitida, deverá conter ou fazer-se acompanhar por este aviso. 

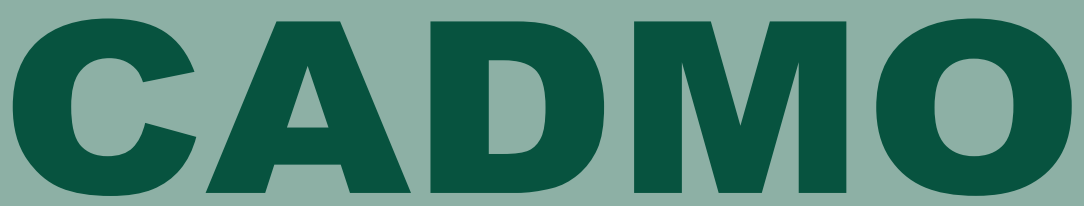

Revista de História Antiga

\author{
Centro de História \\ da Universidade de Lisboa
}

\title{
25
}

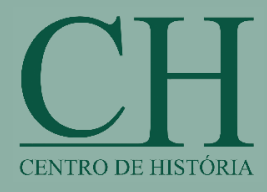

47人

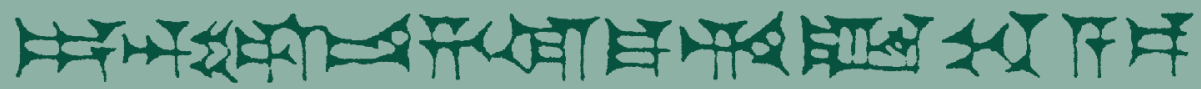

MHNIN AEI $\triangle \mathrm{E} \Theta \mathrm{EA} \Pi \mathrm{\Pi H} \Lambda \mathrm{HIA} \Delta \mathrm{E} \Omega$ 


\title{
MARCO ANTÓNIO, O ORADOR: CARREIRA PÚBLICA E ORATÓRIA
}

\section{MARCUS ANTONIUS, THE ORATOR: PUBLIC CAREER AND ORATORY*}

\author{
João Paulo Simões Valério** \\ Universidade de Lisboa, Centro de História \\ jvalerio@campus.ul.pt
}

Resumo: O presente estudo foi elaborado com o objectivo de abordar a carreira pública e oratória de Marco António, o orador. Era essencial, para um romano da nobilitas, percorrer todas as etapas do cursus honorum para chegar ao topo das magistraturas. António, como veremos, será um exemplo paradigmático de ascensão política em Roma. Tendo sido uma família pouco importante nos inícios do século II a.C., como chegaram os Antónios ao topo do cursus honorum? O método envolve um estudo prosopográfico, especialmente vocacionado para a dissecação das origens desta gens.

Palavras-chave: Marco António; Gens Antonia; cursus honorum; Oratória; Política Romana.

Abstract: This paper was elaborated for the purpose of approaching the public career and oratory of Marcus Antonius, the orator. For a member of the nobilitas, it was essential to go through all the stages of the cursus honorum in order to reach the top of the magistratures. Antonius, as we shall see, will be a paradigmatic example of political ascension in Rome. Having been a minor family in the early second century BC, how did the Antonii reach the top of the cursus honorum? The method involves a prosopographical study, especially devoted to dissecting the origins of this gens.

Keywords: Marcus Antonius; Gens Antonia; cursus honorum; Oratory; Roman Politics.

* Submissão: 27/09/2015; aceitação: 03/06/2016.

Este texto procura desenvolver e completar parte da nossa tese de mestrado, Valério (2014). Ao Professor Doutor Nuno Simões Rodrigues e ao Mestre Gabriel Silva se agradece a revisão do texto.

** Bolseiro de Investigação de Doutoramento pela Faculdade de Letras da Universidade de Lisboa. 


\section{Introdução}

A nossa fonte primária para a reconstrução da vida de António é Marco Túlio Cícero. O orador de Arpino legou-nos várias obras em que retrata a eloquência de Marco António ${ }^{1}$. Em De Oratore, Lúcio Licínio Crasso $^{2}$ e Marco António são os principais interlocutores do diálogo. Até que ponto as ideias transmitidas por António seriam verdadeiras? Sabemos pelo próprio Cícero que o «António» de De oratore é uma persona ${ }^{3}$.

Em Brutus, Cícero reconstrói a história da eloquência romana. O par Crasso e António representa o pináculo da eloquência latina. Segundo a narrativa do orador, graças aos dois sublimes oradores latinos, Roma, pela primeira vez, tornou-se equivalente à Grécia ${ }^{4}$. É, também, de assinalar que Cícero conheceu pessoalmente Marco António5:

De Antonio vero, quamquam saepe ex humanissimo homine, patruo nostro, acceperamus, quemadmodum ille vel Athenis vel Rhodi se doctissimorum hominum sermonibus dedisset, tamen ipse adulescentulus, quantum illius ineuntis aetatis meae patiebatur pudor, multa ex eo saepe quaesivi.

A respeito de António, ainda que amiúde tenhamos ouvido do nosso tio paterno, homem muito culto, de que modo ele se entregara, quer em Atenas, quer em Rodes, aos diálogos de homens doutíssimos; eu próprio, porém, ainda rapaz, interroguei-o frequentemente na medida em que mo permitia $o$ pudor da minha tenra idade.

Apesar das condicionantes, podemos, comparando com outras fontes como Quintiliano (Institutio Oratoria) ou Valério Máximo (Factorum ac dictorum memorabilium libri), cotejar e acrescentar ao testemunho de Cícero. Procuraremos, igualmente, na nossa abordagem, discutir a carreira pública de António e a importância da oratória na sua ascensão no senado.

O nosso estudo não estaria completo, no entanto, sem examinar qual a importância da gens Antonia em Roma. A análise torna-se pertinente na medida em que é essencial compreender as origens de Marco António. Tendo sido uma família pouco importante nos inícios do século II, como chegaram os Antónios ao topo do cursus honorum?

\footnotetext{
Vide e.g. Cic. de Orat. Brut. et Orat.

2 Pretor em 98, cônsul em 95 e censor em 92. Broughton (1952) 4, 11, 17. Crasso e António foram considerados por Cícero como os melhores oradores da geração anterior a si. Cf. Cic. Brut. 138.

3 Cic. Fam. 7.32.2: quae sunt a me in secundo libro de Oratore per Antoni personam disputata de ridiculis (...) et arguta apparebunt, ut sacramento contendas, mea non esse. Wisse (2002) 377.

4 Cic. Brut. 138-200c.

5 Cic. de Orat. 2.3.
} 


\section{Para uma prosopografia dos Antonii}

Quando percorremos o CIL, nomeadamente os Fasti Capitolini, encontramos esparsos registos dos Antónios. O primeiro aponta-nos para um Tito António Merenda, membro do decenvirato de 450 que estabeleceu as famosas leges duodecim tabularum ${ }^{6}$. Tito ainda combateu, com os outros decênviros, a tribo dos Équos, tendo sido derrotado no Monte Agildo $^{7}$. O cognomen Merenda ${ }^{8}$ suscitou alguma discussão em relação à sua origem. Dionísio de Halicarnasso afirma que Tito António estaria entre os patrícios escolhidos por Ápio Cláudio; Tito Lívio, por outro lado, assevera que todos os decênviros seriam de origem patrícia ${ }^{9}$. Algumas obras de referência seguem a sugestão das fontes ao colocarem a família de Tito António no ramo patrício da gens Antonia ${ }^{10}$, outras, no entanto (mais recentes), seguem a opção plebeia ${ }^{11}$. Como, porém, assinala Broughton, só se conhecem ligações dos Antónios com plebeus ${ }^{12}$. Esta condição faz-nos crer que não haveria um ramo patrício desta família. Talvez o cognome tivesse algo que ver com alguma especial apetência por algum tipo de comida ${ }^{13}$, ou mesmo outra peculiaridade do decênviro ${ }^{14}$. É provável que o próximo António que encontramos, Quinto António Merenda,

$6 \quad$ Cf. Liv. 3.35.1, 3.413.41ss.; D.H. 10.58.4. Broughton (1951) 46-47. Sobre os decênviros como autores das leis vide Cic. Rep. 2.63 contra Diodoro Sículo que aponta para os cônsules de 449. D.S. 12.126.1.

7 D.H 11.23.1-6; Liv. 3.38.1-13, 41.7-13, 42.1-7.

8 Cognome raro, dado que só temos referência do seu uso nos Antonii e nos Cornelii. Vide Kajanto (1982) 340.

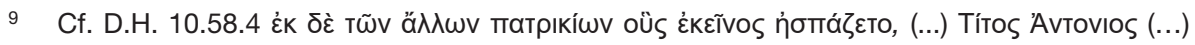

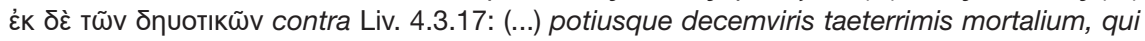
tamen omnes ex patribus erant, quam optimis regum (...).

10 "The Merenda branch of the Gens Antonia was patrician (...)" Smith (1872) 1047. Assinalando a opinião contrária de Niebuhr, Jülicher opta, no entanto, por afirmar que Tito António é patrício: "T. Antonius Merenda (...) Patricier, aber bereits Niebuhr beide mit Recht als Plebejer bezeichnet." Jülicher (1894) 2575.

11 "Plebeian gentile name, in evidence from the $5^{\text {th }}$ cent. BC (...)" Elvers (2002) 801. Jülicher, (1894) e o Oxford Classical Dictionary não dispõem de qualquer entrada sobre a gens Antonia.

12 Broughton (1951) 47 n. 1.

13 Como assinala Kajanto, "The original bearers of these cognomina may have had a particular liking for the relevant kind of food." A autora refere outros exemplos relacionados com comida que, curiosamente, se tornaram raros no final da República: “ (...) Arvina, Canina, Catilina (...) Porcina." Kajanto (1982) 91.

14 “(...) occurrence of an occasional cognomen reflects individual peculiarities." Douglas (1958) 63: OLD mereo 1 "(usu. Act.) To receive as one's wage or reward, earn (Money)» ou 2 stipendia ere «To draw pay as soldier, serve.» 
tribunus militum consular potestate em $422^{15}$, seja filho de Tito António, mas mais nada se sabe sobre ele. Não encontramos, no entanto, mais registos da gens Antonia para o século V. Se houve um ramo patrício da gens Antonia, ter-se-á extinguido, dado que não deparámos com mais referências sobre esta familia.

No século IV há apenas referência a um Marco António que, em 334, foi nomeado magister equitum pelo senado, na guerra contra os Samnitas $^{16}$. No século III, a gens Antonia vagueia pela obscuridade, estando completamente ausente das nossas fontes. Quanto ao século II, só temos registos de quatro Antónios: um dos oficiais do pretor L. Emílio Régilo na guerra contra Antíoco III em 19017; um tribuno da plebe em 16718; outro foi um dos três legados enviados por Emílio Paulo ao rei Perseu da Macedónia depois da vitória em Pidna em $168^{19}$. Por fim, chegamos a Marco António, o homo eloquens.

Como denotamos nesta breve cronologia dos Antónios, a gens Antonia estava longe de ser uma família proeminente na oligarquia senatorial romana. De facto, não conseguiu nomear um único cônsul para a República, embora alguns membros da família tenham conseguido cargos de relevância, principalmente no século $V$. A falta de continuidade nos postos mais altos da República sugere uma dificuldade em manter-se no círculo restrito da elite senatorial. Atendendo a estes dados, poderemos traçar com maior pertinência a carreira de Marco António, o orador.

\section{Cursus honorum e oratória}

Marco António, o orador, nasceu em $143^{20}$. Este iniciou o seu cursus honorum em 113, como questor. Cícero, em Brutus, sugere que António,

15 Liv. 4.42.2: Senatus, cum odio Semproni consulare nomen offenderet, tribunos militum consulari potestate creari iussit (...) Q. Antonius Merenda (...) Klebs (1894) 2633; Elvers (2002) 806; Smith (1872) 1047.

16 Liv. 8.17.3-4: (...) ex auctoritate senatus dictus $P$. Cornelius Rufinus, magister equitum $M$. Antonius.

17 Liv. 37.32.8: Huic opera intentis supervenit Q. Antonius a praetore missus (...)

18 Liv. 50.21.40: Huic actioni M. Antonius et M. Pomponius tribuni plebis aversabantur. Broughton (1951), 433. Plb. 30.4.5-6.

19 Aulo António. Liv. 50.4.7: Missi sunt tres legati, P. Lentulus, A. Postumius Albinus, A. Antonius.

20 Baseado na data de nascimento de Lúcio Licínio Crasso - 3 anos mais novo que António presente em Brutus de Cícero. Cic. Brut. 161: His enim consulibus eam legem suasit quibus nati sumus, cum ipse esset $Q$. Caepione consule natus et $C$. Laelio, triennio ipso minor quam Antonius (...); Smith (1872) 213 apresenta um Gaio António como pai de Marco António. Não encontrámos, no entanto, nenhuma fonte que comprove essa hipótese. Para outras hipó- 
devido à riqueza da sua prática forense, seria bastante requisitado21. É possível aventar que M. António ocupasse, antes da questura, a maior parte do seu tempo em causas forenses, que lhe teriam granjeado popularidade em Roma ${ }^{22}$. A sua carreira pública não começou, contudo, da melhor forma ${ }^{23}$.

A primeira prossecução pública de António registada foi em $112^{24}$, contra o cônsul de 113, Gneu Papírio Carbão ${ }^{25}$, que ganhou grande impopularidade por causa da derrota contra os Cimbros; Papírio Carbão foi, igualmente, acusado de perduellio na conduta da guerra, suicidando-se antes do veredicto ${ }^{26}$. No ano de 103, Marco António defendeu o ex-cônsul Gneu Málio Máximo27; Tito Lívio culpou o procônsul da Gália, Quinto Servílio Cepião, pela derrota perante os Cimbros (por se ter recusado a juntar forças com Málio Máximo). O procônsul foi exilado em 10428; todavia, Málio Máximo não escapou a um julgamento; numa segunda fase, o tribuno da plebe Lúcio Apuleio Saturnino propôs um plebiscito para condenar Cepião e, apesar da defesa de António, o ex-cônsul foi condenado ao exílio ${ }^{29}$. O ano de 103 também trouxe outra novidade: no tribunato de Saturnino, foi estabelecido um novo tipo de crime conhecido como maiestas. Adiante veremos como António lidou com esse tipo de crime.

Em 102, António foi eleito pretor com poder proconsular para a Cilí$\mathrm{cia}^{30}$, onde foi bem-sucedido ao derrotar os piratas na região. Assim, além dos seus dotes de oratória, provou ter dons militares. Foi conce-

teses sobre a data de nascimento de António vide Fantham (2004) 28 n. 4 apud. Summer (1972) 93-97.

21 Cic. Brut. 207: Propterea quod Antonius, qui maxime expetebatur facilis in causis recipiendis erat.

22 Fantham (2004) 429.

23 O orador foi acusado de ter tido relações sexuais com uma vestal, o que constituía especificamente crime de incestum. Val. Max. 6.8.1: M. Antonius, avorum nostrorum temporibus clarissimus orator, incesti reus agebatur. O questor estaria já no porto de Brundísio à espera de embarcar para a Ásia para servir como questor, quando soube da acusação. Apesar de estar protegido pela magistratura que exercia, António não perdeu tempo e regressou a Roma. O seu regresso voluntário à Urbe foi visto com grande respeito e admiração pelo populus romano, tendo António sido absolvido. Cf. Val Max 3.7.9. Gruen considera a sua defesa como "first step in a brilliant oratorical career." Gruen (1968) 63.

24 Vide ORF 225-226.

25 Broughton (1951) 535.

26 Que certamente Ihe seria desfavorável. Cf. Cic. Fam. 9.21.3.

27 Cônsul em 105. Broughton (1951) 555.

28 Liv. 6.7: Caepionis, cuius temeritate clades accepta erat, damnati bona publicata sunt, primi post regem Tarquinium, imperiumque ei abrogatum (...) Cf. Cic. de Orat. 2.124.

29 Cic. de Orat. 2.125. Defesa de António em Cic. de Orat. 2.198-199.

30 Broughton (1951) 568. 
dido a António um triunfo, provavelmente em Dezembro do ano $100^{31}$. Além do mérito reconhecido, o orador escapou a um clima de agitação em Roma; Gaio Mário era o cônsul do ano 100 e teve de controlar a agitação provocada por Saturnino ${ }^{32}$. Apesar de estar fora do bulício, Marco António chegou a Roma ainda a tempo de ser eleito cônsul para $99^{33}$. O único aspecto que sabemos do consulado de M. António foi que se opôs a uma nova lei agrária, proposta pelo tribuno Sexto Tício, simpatizante de Saturnino ${ }^{34}$. O tribuno foi processado no ano seguinte ${ }^{35}$ e António foi uma das testemunhas de acusação ${ }^{36}$. Como cônsul, não nos chegaram registos de discursos proferidos.

No ano seguinte, já ex-cônsul, proferiu um dos mais importantes da sua carreira: a defesa do velho oficial de Gaio Mário, Mânio Aquílio ${ }^{37}$, acusado de extorsão e peculato, enquanto governador da Sicília em 9938. O discurso dramático do orador foi transmitido por Tito Lívio ${ }^{39}$ e por Cícero em De Oratore ${ }^{40}$, In Verrem e Pro Flacco ${ }^{41}$. Aquílio foi absolvido ${ }^{42}$. Esta defesa e o testemunho contra Sexto Tício terá tido

31 O seu mandato durou 2 anos. Cic. de Orat. 1.82: tamen cum pro consule in Ciliciam proficiscens. Liv. 68: M. Antonius praetor in Ciliciam maritimos praedones persecutus est. 44: Piratae in Cilicia a Romanis deleti. Broughton (1951), 568.

32 Sobre o clima político em Roma nesse período vide Broughton (1951), 574-576.

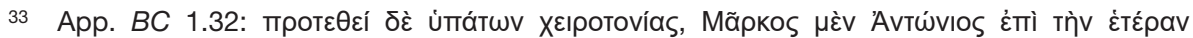

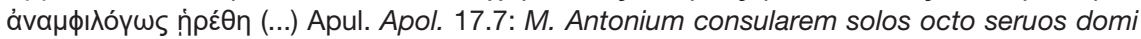
habuisse (...) Badian considera que as conexões com Mário foram essenciais para a sua eleição. "He, being outside the city with imperium, took no active part in the events that led to their destruction but he certainly supported the action of Marius and the Senate at the time, and as consul, opposed the surviving supporters of Saturninus." Badian (1964) 47.

34 Broughton (1952) 1-2.

35 Val. Max. 8.11(damn).3. O seu caso foi interessante dado que Cícero o aproveitou no pro Rabirio Perduellionis Reo. Cic. Rab. Perd. 24.

36 Cic. de Orat. 2.48: ac nonnunquam etiam accuratius, ut mihi etiam necesse fuit in Sex. Titium, seditiosum civem et turbulentum. 2.265: ut cum Sex. Titius se Cassandram esse diceret, Multos, inquit Antonius, possum tuos Aiaces Oileos nominare.

37 Vide caracterização do julgamento em May (2002) 62 n. 32.

38 Broughton (1952) 2-3.

39 O livro 70 perdeu-se, mas no epítome é dito que a única fonte de Lívio foi Cícero. Liv. 70 : Cicero eius rei solus auctor.

40 Crasso faz a introdução da inuentio no capítulo 124 e António argumenta nos capítulos 194 a 196.

41 Vide Cic. Ver. 2.5.3: Venit enim mihi in mentem in iudicio M'Aquilii quantum auctoritatis quantum momenti oratio M.Antonii habuisse existimata sit; Flac. 98 M'. Aquilium patres nostri multis avaritiae criminibus testimoniisque convictum, quia cum fugitivis fortiter bellum gesserat, iudicio liberaverunt. consul ego nuper defendi C. Pisonem; qui, quia consul fortis constansque fuerat, incolumis est rei publicae conservatus. defendi item consul L. Murenam, consulem designatum (...)

42 Gaio Mário também teve um papel essencial na absolvição. Cic. de Orat. 2.196: Cum C. Marius maerorem orationis meae praesens ac sedens multum lacrimis suis adiuvaret, cum- 
um impacte bastante grande em Roma. Talvez tenha ajudado a que, no mesmo ano, fosse eleito um dos censores para 9743; como censor, junto com Lúcio Valério Flaco, António expulsou Marco Durónio ${ }^{44}$, tribuno da plebe no mesmo ano, por causa de uma lei sumptuária ${ }^{45}$. António foi acusado de ambitus ${ }^{46}$ pelo ex-senador ${ }^{47}$.

Em 9548, António defendeu Gaio Norbano, questor de António na Cilícia $^{49}$ e tribuno da plebe em 103, acusado de minuta maiestas ${ }^{50}$. Cícero reconstrói o discurso no segundo livro de De Oratore ${ }^{51}$. António utiliza a sua auctoritas para defender o acusado ${ }^{52}$. Não servindo este argumento, 0 orador apoia-se na história de Roma, relembrando a disputa entre patrícios e plebeus, a expulsão dos reis, a criação de tribunos da plebe, entre outros episódios da história romana ${ }^{53}$. O recurso à história romana por parte de M. António serve para demonstrar que a constante tensão em Roma serviu bons exempla. Assim sendo, Norbano não poderia ser condenado pelo crime de maiestas. António, por sua vez, falou de Quinto Cepião para desviar a ira do povo romano ${ }^{54}$, conseguindo a absolvição de Norbano ${ }^{55}$.

que ego illum crebro appellans collegam. Quint. Inst. 2-15.7-8: Nam et Manium Aquilium defendens Antonius, cum scissa veste cicatrices qua sis pro patria pectore adverso suscepisset ostendit, non orationis habuit fiduciam, sed oculis populi Romani vim attulit: quem illo ipso aspectu maxime motum in hoc, ut absolveret reum, creditum est. Badian associa o papel de Mário como prova que António era mariano. Badian (1964) 35-36.

43 Broughton (1952) 6-7. Cícero afirma que António, na sua censura, adornou os rostra com os despojos da guerra contra os piratas na Cilícia. Cic. de Orat. 3.10: (...) quaeque censor imperatoriis manubiis ornarat, positum caput illud fuit, a quo erant multorum [civium] capita servata (...). Badian considera que o apoio do Arpinate Mário foi essencial para a eleição. Cf. Badian (1964) 47-48. Broughton (1952) 7.

45 Val. Max. 2.9.5: M. autem Antonius et L. Flaccus censores Duronium senatu moverunt, quod legem de coercendis conviviorum sumptibus latam tribunus plebi abrogaverat.

46 Lintott (1996) 70-71. “(...) In 181 BC a lex Cornelia Baebia instituted a system of non-capital trials, which was developed in the late republic by further laws about ambitus and related matters (...) These laws seem to have been a response to greater competition for office."

47 Cic. de Orat. 2.274: Antoni, Mancia, cum audisset te censorem a M. Duronio de ambitu postulatum (...) Sobre a possiblidade de um cidadão privado processar um censor em funções vide Alexander (1990) 43.

48 Data aceite pela maior parte dos estudiosos. Vide Badian (1964) 35.

49 Vide Cic. de Orat. 2.197-202 e em especial 200. App. BC. 1.91. Esta defesa é um claro exemplo da relação quase paternal que era suposto existir entre o magistrado sénior e o seu questor. Richardson (1994) 581.

50 Broughton (1951), 563-4. Um homo nouus. Mais pormenores em Badian (1964) 84-86.

51 Cic. de Orat. 2.107-109, 124, 188, 197-204.

52 Segundo Val. Max. 7.3.5 (...) enim capite non solum eloquentia sua uti, sed etiam verecundia abuti erat paratus.

53 Cf. Cic. de Orat. 2.107-109, 124, 188 e em especial 197-204.

54 Cic. de Orat. 2.199.

55 Cic. de Orat. 2.202-203. 
Em 91, no único julgamento que opôs António a outro ilustre orador da época, Licínio Crasso, Marco António defendeu Marco Mário Gratidiano ${ }^{56}$. A sua última defesa foi a favor de Quinto Márcio ${ }^{57}$.

O último discurso de António foi, provavelmente, em 90, em defesa da lex uaria de maiestate, proposta pelo tribuno Quinto Vário Híbrida ${ }^{58}$. Não se sabe o papel do orador na Guerra Social; contudo, segundo Badian, António serviu como legado ao lado da facção de Sula ${ }^{59}$. Em 87, em plena guerra civil, foi uma das vítimas da purga de Gaio Mário em Roma ${ }^{60}$. Não se sabe a razão do assassínio, porém, é provável que tenha sido um acto de vingança por parte de Mário61. Mesmo na sua morte, a eloquência de António é assinalada ${ }^{62}$. Apiano relata uma narrativa no mesmo sentido, embora menos «romântica»63; a cabeça de António foi exposta nos ros-

56 Sobrinho de Gaio Mário. Futuro pretor em 85. Broughton (1952), 57. Levado a tribunal por não ter comunicado a Gaio Sérgio Orata, no contrato da venda de uma casa, que esta se encontrava hipotecada. Cic. Off. 3.67. Cic. de Orat. 1.178: nuper, cum ego C. Sergi Oratae contra hunc nostrum Antonium iudicio privato causam defenderem (...) Cf. Cic. Brut. 168; Leg. 3.

57 Cic. de. Orat. 2.125: Quid ego de Cn. Manli, quid de Q.Regis commiseratione dicam? Cônsul em 118. Broughton (1951) 527.

58 Lei aplicada a todos os cidadãos romanos que incitavam os aliados (estamos nos princípios da chamada Guerra Social) a se revoltar. Broughton (1952) 25. Asc. Pis. 79 c: M. Plautius Silvanus tribunus plebis Cn. Pompeio Strabone L. Porcio Catone coss., secundo anno belli Italici cum equester ordo in iudiciis dominaretur, legem tulit adiuvantibus nobilibus; quae lex vim eam habuit quam Cicero significat: nam ex ea lege tribus singulae ex suo numero quinos denos suffragio creabant qui eo anno iudicarent. Ex eo factum est ut senatores quoque ineo numero essent, et quidam etiam ex ipsa plebe.

59 O académico propõe, através das listas de legados (o nome de António está ausente); no entanto o autor interpreta o passo de Cic. Brut. 30 como prova da divisão. A argumentação baseia-se na posição dos cônsules de 90 - início da Guerra Social - Lúcio Júlio César e Públio Rutílio Lupo. Cf. Broughton (1952) 25. Nomes como Sula e Públio Licínio Crasso (cônsul em 97) serviram com Lúcio Júlio César; Gaio Mário ou Quinto Servílio Cepião serviram com Públio Rutílio Lupo. Broughton (1952) 28-29. Vide argumentação em Badian (1964) 52-56. Assim, Badian identifica o casamento de Marco António Crético com a filha de Júlio César com uma clara aproximação do orador à facção dos boni. "M. Antonius had probably, at some time after 95 and before 91, followed the Caesars, as they had followed Catullus, into the camp of the boni." Badian (1964) 56.

60 Liv. 80: (...) et omnibus adversae partis nobilibus trucidatis, inter quos M. Antonio eloquentissimo viro (...)

61 Mário parece não ter perdoado a deserção de António para os partidários de Sula. Vide Badian (1964) 56-58.

62 Segundo Val. Max. 8.9.2.

63 App. BC 1.72. 
tra, junto com as outras vítimas da purga ${ }^{64}$. Valério Máximo conta uma história bizarra de como Mário rejubilou pela morte de António65.

\section{Eloquentia}

A eloquência de Marco António foi determinante para o seu êxito político. Cícero é particularmente elogioso em relação à oratória de António em Brutus ${ }^{66}$ :

Quam multi enim iam oratores commemorati sunt (...) cum tamen spisse atque vix, ut dudum ad Demosthenem et Hyperidem, sic nunc ad Antonium Crassumque pervenimus! Nam ego sic existimo, hos oratores fuisse maximos et in his primum cum Graecorum gloria Latine dicendi copiam aequatam.

Quão numerosos foram os oradores já recordados (...) Não foi todavia sem lentidão e sem dificuldade que chegámos, há pouco, a Demóstenes e a Hipérides e agora a António e a Crasso. Efectivamente esta minha convicção assenta no facto de estes dois terem sido os nossos melhores oradores e de ter sido por meio deles que, pela primeira vez, a eloquência latina logrou equivaler-se à glória da Grécia.

Os elogios continuam ao evidenciar, em Brut. 139, a discussão das cinco partes do sistema retórico: inuentio, dispositio, memoria, elocutio e actio $^{67}$. Cícero enfatiza, sobretudo, a memória do orador ${ }^{68}$ :

Erat memoria summa, nulla mediationis suspicio;

Possuía uma memória prodigiosa que excluía liminarmente a hipótese de qualquer preparação prévia.

\section{Em Brut. 141, o discurso laudatório continua ${ }^{69}$ :}

Quo in genere quia praestat omnibus Demosthenes, idcirco a doctis oratorum

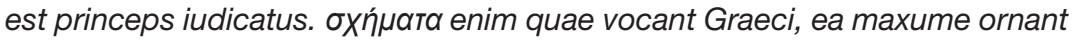
oratorem eaque non tam in verbis pingendis habent pondus quam in inluminandis sententiis. sed cum haec magna in Antonio tum actio singularis; quae si partienda est in gestum atque vocem, gestus erat non verba exprimens,

64 Cic. de Orat. 3.10: Iam M. Antoni in eis ipsis rostris, in quibus ille rem publicam constantissime consul defenderat (...) Curiosamente, quarenta e quatro anos depois, Cícero teria um desfecho semelhante por ordem do neto do orador, do qual não só a cabeça foi exposta, mas também as mãos do Arpinate (que escreveram as infames orationes Philippicae.)

65 Val. Max. 9.2.2: idem caput $M$. Antoni abscisum laetis manibus inter epulas per summam animi ac verborum insolentiam aliquamdiu tenuit, clarissimique et civis et oratoris sanguine contaminari mensae sacra passus <est>, atque etiam P. Annium, qui id attulerat, in sinum suum recentis caedis vestigiis aspersum recepit.

66 Cic. Brut. 138 em trad. adaptada de Fernandes (1987).

67 Cic. Brut. 139.

68 Cic. Brut. 139.

69 Cic. Brut. 141. 
sed cum sententiis congruens: manus humeri latera supplosio pedis status incessus omnisque motus cum verbis sententiisque consentiens; vox permanens, verum subrauca natura. sed hoc vitium huic uni in bonum convertebat.

Demóstenes excedeu todos nesta arte [arte retórica] e foi, por isso mesmo, considerado pelos críticos o príncipe dos oradores. Com efeito, aquelas figuras a que os gregos chamam (figuras) são o maior ornamento do discurso e produzem efeito não tanto no colorido das palavras, mas sobretudo no brilho dos pensamentos. António não só possuía estas qualidades. Possuía principalmente uma acção singular. Se a acção deveria ser dividida em gesto e voz, nele o gesto não exprimia as palavras, mas correspondia aos pensamentos; conservava um tom de voz um pouco rouco por natureza. Mas este defeito nele convertia-se em virtude.

Em De Oratore, o senador coloca em evidência a capacidade de persuasão e manipulação das audiências de António ${ }^{70}$. Além disso, Cícero elogia a utilização dos meios aristotélicos de persuasão - ethos e logos - enaltecendo, principalmente, a utilização do pathos por parte de António ${ }^{71}$.

Nas Tusculanae disputationes, o advogado romano afirma que Marco António foi o mais eloquente dos oradores que já ouviu ${ }^{72}$. Segundo o orador, António nunca publicou os seus discursos ${ }^{73}$.

António terá escrito um pequeno tratado sobre arte oratória (de ratione dicendi $)^{74}$, tendo sido o segundo tratado de retórica a ser escrito em Roma ${ }^{75}$. Segundo Quintiliano, o tratado estava incompleto ${ }^{76}$; e além das afirmações de Cícero ${ }^{77}$ e de Quintiliano, pouco sabemos sobre o manual78; Rawson afirma que, muito provavelmente, nem Cícero nem

\footnotetext{
70 Cic. de Orat.. 2.122-124.

71 Cic. de Orat. 1.189: Ethos e pathos fazem parte da inuentio em de Orat. Rabbie (2007) 209.

72 Cic. Tusc. 5.55 (...) M. Antonii, omnium eloquentissimi, quos ego audierim (...)

73 Cic. de Orat. 2.8; Orat. 132. Para razão desta opção vide Cic. Clu. 140. Cf. Val. Max. 7.3.5.

74 Cic. Brut. 163. Quint. Inst. 3.6.45-46 Produto da sua experiência como orador: ipsaque illa, quae in commentarium meum rettuli, sunt eiusmodi, non aliqua Mihi doctrina tradita, sed in rerum usu causisque tractata. Cic. de Orat. 1.208.

75 O primeiro foi de Catão, o Censor. Quint Inst. 3.1.19: Romanorum primus, quantum ego quidem sciam, condidit aliqua in hac materiam M.Cato, post M. Antonius [ille censorius] inchoavit (...)

76 Quint Inst. 3.1.19: nam hoc solum opus eius atque id ipsum inperfectum manet.

77 O tratado foi, segundo Cícero, publicado sem a autorização de António. Cic. de Orat. 1.95: Tumque ego, hac eadem opinione adductus scripsi etiam illud quodam in libelo qui me imprudente et invito excidit, et pervinit in manus hominum (...) Vide ORF 236-237.
} 
Quintiliano tiveram acesso ao pequeno tratado ${ }^{79}$. Apesar da eloquência, António admitia a sua ignorância em relação à lei80 e à cultura grega ${ }^{81}$.

Para denegrir a imagem de Marco António, futuro triúnviro e neto deste orador, o orador de Arpino estabeleceu um paralelo com António na Segunda Filípica, mais propriamente na transitio para a confirmatio em que Cícero ataca as competências de António (neto) como orador ${ }^{82}$. Este passo da Segunda Filípica, que é um ataque directo às competências do futuro triúnviro como orador, não poderia estar completo sem a analogia com o avô de Marco António. O ataque também servia para aplicar o locus de degeneração familiar, já que o cônsul seria um representante indigno dos Antonii 83 . Além desse objectivo, Cícero demonstrava, mais uma vez, a admiração por Marco António, o orador.

\section{Conclusão}

Podemos aferir que, apesar da grande deferência que a nossa fonte principal, Cícero, tinha pelo orador latino, Marco António foi, a par de Licínio Crasso, o expoente máximo da oratória latina nos finais do séc. II e inícios do séc. I a.C. António, além da obra de Cícero, é bastante referido na Institutio Oratoria de Quintiliano e nos Factorum ac dictorum

79 Como avança Rawson, "Cicero would probably have mentioned any intervening Latin writings in the De Oratore, and Quintilian clearly knew nothing else." Rawson (2002) 146 n. 5.

80 Cic. de Orat. 1.172-248.

81 Mais do que ignorância, talvez desinteresse. Vide Cic. de Orat. 2.156-160. A surpresa de Júlio César Estrabão Vopisco em relação aos conhecimentos de grego por parte de António é elucidativa: Quid est inquit, Catule? Caesar; ubi sunt, qui Antonium Graece negant scire? Quot historicos nominavit! (...) Id mehercule inquit Catulus, admirans, illud iam mirari desino quod multo magis ante mirabar, hunc, cum haec nesciret, in dicendo posse tantum. Cf. Cic. de Orat. 2.59.

82 Cic. Phil. 2.42: Vide auctem quid intersit inter te et auum tuum. Ille sensim dicebat quod causae pro desset; tu cursim dicis aliena.

83 Vide Craig (2004) 192. Outros ataques a António como orator malus podem ser encontrados em Cic. Phil 2.8: homo diserte; 11: homo sapiens non solum eloquens; 18: homo disertus; 28: homo acutus 86: eloquentiam tuam. Outros em Cic. Phil. 2.9; 19; 20; 29; 30; 31-32; 43. Na XIV Filípica, Cicero afirma que a fibra moral dos Antonii decaiu, Cic. Phil. 14.9: Quas enim turpitudines Antonii libenter cum dedecore subierunt easdem per vim laetantur aliis se intulisset, o que sugere uma comparação com o avô deste. Em Cic. Phil. 3.35 toda a sua domus é atacada: (...) Nostis insolentiam Antoni, nostis amicos, nos totam domum. As críticas são estendidas aos seus irmãos Gaio (10.10) e Lúcio (3.31). 
memorabilium libri de Valério Máximo ${ }^{84}$. Desta forma, concordamos com Steel que afirma ${ }^{85}$ :

Although nothing can be said about the contents of the speeches themselves, a couple of anecdotes do indicate that Antonius was a striking courtroom performer and highly skilled in manipulating his audience's emotions.

Por outro lado, a eloquência vertida na política, que Cícero tanto admirava, estava presente em António. Como atestámos, Marco António foi um autêntico homo nouus e foi nos tribunais que ganhou prestígio para os Antonii ${ }^{66}$. Consequentemente, podemos afirmar, ainda que com prudência e com o apoio da prosopografia dos Antonii no séc. Il que, sem a auctoritas, dignitas e honor do orador, a gens Antonia teria passado em relativa obscuridade no século I. Analogamente, temos que nos lembrar do contexto da época em que Marco António, o orador, viveu, que veio culminar na terrível guerra civil entre Mário e Sula. António conseguiu erguer a sua gens num período marcado pela ascensão dos generais ${ }^{87}$.

84 Embora grande parte das fontes dos autores seja o próprio Cícero. Quintiliano, o grande retor da era dos Flávios, era um grande admirador de Cícero. Advogava um regresso ao modelo ciceroniano - embora, na verdade, seja mais uma reinterpretação de Cícero. O seu objectivo era recuperar o papel do orador como uir bonus dicendi peritus (o termo é de Catão, o Censor). Talvez seja igualmente um reflexo do aclamado retorno ao mos maiorum proclamado por Domiciano. Era, assim, pertinente retomar alguns ensinamentos de António transmitidos por Cícero. Para mais sobre Quintiliano, vide Conte (1999) 841-849; Alberte (2007) 589-603. A obra de Valério Máximo, autor do principado de Tibério, é, na feliz frase de Citroni (2006) 682, "Uma Summa da ética republicana para a sociedade imperial." O exemplum de Marco António, como modelo de virtude, encaixava perfeitamente nos tradicionais valores republicanos que Máximo recuperou na sua opus Factorum ac dictorum memorabilium libri. Para mais sobre Valério Máximo, vide Albrecht (1999) 986-994.

Steel (2007) 242.

86 Fantham (2004) 48.

87 Vide e.g. Sal. Jug. sobre o ambitus dos generais como facto decisivo para a decadência romana, "The rise of the warlords", como refere Gwynn (2012) 79. O êxito de António também se explica pelo facto de, desde 149, por uma lei passada pelo tribuno da plebe Lúcio Calpúrnio Pisão Frúgi (Broughton (1951) 459), ter sido instituída a primeira quaestio perpetua que permitia julgar crimes de concussão cometidos pelos magistrados designados para o governo das províncias; com o tempo, estenderam-se a vários outros tipos de delito (actos de lesa-majestade, peculato, corrupção eleitoral, homicídio, ferimentos e agressões, etc.) Esta situação levou a uma luta pelo controlo dos júris entre os senadores e equestres. A condenação de um acusado poderia levá-lo à ruína. Marco António aproveitou, claramente, este clima. Como aponta Narducci (2006) 239, "O êxito na acusação comportava privilégios muito importantes, entre os quais a obtenção da cidadania para o próprio e para os seus descendentes. (...) Tais oradores encontravam nos processos a oportunidade de se tornarem conhecidos e apreciados mediante o ataque conduzido contra membros da aristocracia senatorial." O exemplo de Marco Túlio Cícero é o mais paradigmático desta situação (embora este apontasse a defesa como a mais apropriada. Cf Cic. Off. 2.49). Não nos parece descabido, porém, apontar paralelamente a situação de António. 
O orador teve três filhos: Antónia ${ }^{88}$, Gaio António Híbrida e Marco António Crético, pai do futuro triúnviro.

Marco António foi um claro exemplum de homo eloquens e homo politicus. A sua carreira pública possibilitou um prestígio que os futuros Antónios não desperdiçaram. Basta atentar nas carreiras de êxito dos filhos do orador: Gaio António Híbrida, por exemplo, chegou a cônsul em 63. Através do comentário de Ascónio Pediano In senatu in toga candida contra $C$. Antonium et $L$. Catilinam competitores ${ }^{89}$, sabemos que a eleição de Gaio António ficou muito a dever à reputação de seu pai90. Marco António Crético casou com uma Júlia ${ }^{91}$ e foi pretor em 74 , sendo- Ihe concedido imperium infinitum para combater os piratas em todo 0 Mediterrâneo ${ }^{92}$. É provável que o êxito do orador no combate aos piratas na Cilícia tenha servido como auctoritas para a nomeação de Crético. Por fim, o facto de António ter, possivelmente, pertencido ao colégio de áugures, poderá ter sido determinante para a eleição para augur do seu neto e futuro triúnviro, Marco António93.

88 Desconhece-se se teve descendência. Segundo Plutarco, foi raptada por piratas. Plut. Pomp. 24.6. Baseando-se no testemunho de Cic. Leg. Man. 33 alguns autores põem a hipótese desta ser filha de Marco António Crético. Vide Tansey (2010) 656-658 com bibliografia. Cf. igualmente App. Mith. 93.

89 Vide Lewis (2006) 165. Discurso de Cícero durante a campanha de 64 para o consulado. 0 discurso original de Cícero não sobreviveu.

90 Asc. Tog. 94C: Antonius pauculis centuriis Catilinam superavit, cum ei propter patris nomen paulo speciosior manus suffragata esset quam Catilinae.

91 Como foi referido anteriormente, a aproximação de António aos lulli Caesares poderá ter sido decisiva para este casamento. Terá sido o segundo casamento de Crético. Segundo Cícero (Phil. 3.17), M. António Crético terá sido casado com Numitória, filha de Quinto Numitório Pulo que, supostamente, entregou a sua cidade, Fregelas, aos romanos em 125. Bailey (1986) 194 n. 19.

92 "Antonius appointment was to last for three years and to cover the whole coast line of the Mediterranean and its islands up to a distance of eighty kilometers from the sea; his imperium was to be equal with that of any governor with whom he might come into contact." Seager (1994) 213. Gneu Pompeio só conseguirá semelhante honra em 67, graças à lex Gabinia. Para mais pormenores vide Broughton (1952) 146.

93 Schol. Bern. in Lucano 2.121: Marcus Antonius censorius orator et augur (...) "No less effective however would be the positive claim of Mark Antony, a grandson of a revered and famous orator, to the priesthood his grandfather had held. Thus he could draw not only upon the support that Caesar rallied but a good deal of other support for hereditary claim." Broughton (1953) 210; Broughton (1952) 52. O futuro triúnviro foi eleito em 50. Praticamente ignorado pelos académicos, exceptuando Welch. "Although the greater credit for this achievement is rightly given to Caesar and Curio, his election ahead of the older, more influential, L. Domitius Ahenobarbus was facilitated by the support afforded by the pro-Antonian voters of Cisalpine Gaul, and the fact that his grandfather had been an augur." Welch (1995) 185. Bailey (1977a) 97. 


\section{Bibliografia}

A. Alberte (2007), "Quintiliano" in C. Codoñer, ed. História de la Literatura Latina, Madrid, Catedra, 589-603.

M. V. Albrecht (1997), Historia de la literatura romana: desde Andrónico hasta Boecio, vol. I, Barcelona, Herder.

(1999), Historia de la literatura romana: desde Andrónico hasta Boecio, vol. II, Barcelona, Herder.

M. C. Alexander (1990), Trials in the Late Roman Republic. 149 to 50 BC, Toronto, Toronto University Press.

E. Badian (1964), Studies in Greek and Roman History, Oxford, Basil Blackwell.

D. R. S. Bailey (1977a), Epistulae ad Familiares, ed., vol. I, Cambridge, Cambridge University Press.

(1977b), Epistulae ad Familiares, ed., vol. II, Cambridge, Cambridge University Press. (1986), Cicero. Philippics, ed., Cambridge (MS), Harvard University Press.

T. R. S. Broughton (1951), The Magistrates of the Roman Republic, vol. I, New York, American Philological Association.

(1952) The Magistrates of the Roman Republic, vol. II, New York, American Philological Association.

(1953) "Notes on Roman Magistrates: the Augurates of Two Marci Antonii", Historia 2/2, 209-210.

M. Citroni (2006), "Historiografia e Erudição desde Tibério até Cláudio" in M. Citroni, E. E. Consolino, M. Labate et E. Narducci, eds. Literatura de Roma Antiga, Lisboa, Fundação Calouste Gulbenkian, 673-683.

G. B. Conte (1999), Latin Literature. A History, Baltimore, The Johns Hopkins University Press.

C. Craig (2004), "Audience Expectations, Invective and Proof" in J. Powell et J. Paterson, eds. Cicero. The Advocate, Oxford/New York, Oxford University Press, 187-214.

A. E. Douglas (1958), "Roman'Cognomina”, G\&R 2nd ser., 5/1, 62-66.

K. L. Elvers (2002), "Antonius" in H. Cancik and H. Scheneider, eds. Brill's New Pauly, vol. I, H. Cancik et H. Schneider, Leiden/Boston, Brill, 801-806.

E. Fantham (2004), Roman World of Cicero's De Oratore, Oxford, Oxford University Press.

J. S. M. Fernandes (1987), Marco Túlio Cícero. Brutus. Dissertação de Mestrado, Lisboa, Universidade de Lisboa.

P. G. W. Glare, ed. (2012), Oxford Latin Dictionary, Oxford, Oxford University Press.

E. S. Gruen (1968), "M. Antonius and the trial of the Vestal Virgins", RhM 111/1, 59-63.

D. M. Gwynn (2012), The Roman Republic. A Very Short Introduction, Oxford, Oxford University Press.

L. Kajanto (1982), The Latin Cognomina, Roma, G. Bretschneider Editore.

R. G. Lewis (2006), Asconius. Commentaries on speeches of Cicero, ed., Oxford, Oxford University Press.

A. Jülicher (1894), "Antonius" in A. Pauly, G. Wissowa et W. Kroll, eds. Realencyclopädie des classischen Altertumswissenschaft, vol. 1, Stuttgart, J.B. Metzlerscher Verlag, 2577-2582. 
A. W. Lintott (1996). "ambitus" in The Oxford Classical Dictionary, $3^{a}$ ed., S. Hornblower et A. Sparforth eds., Oxford/New York, Oxford University Press.

H. Malcovati, ed. (1955), Oratorum Romanorum Fragmenta, Italy, G.B. Paravia.

J. M. May (2002), "Ciceronian oratory in context" in J. M. May, ed. Brill's Companion to Cicero. Oratory and Rhetoric, Leiden, Brill, 49-70.

E. Narducci (2006), "Oratória e Historiografia entre os séculos II e I a.C." in M. Citroni, E. E. Consolino, M. Labate et E. Narducci, eds. Literatura de Roma Antiga, Lisboa, Fundação Calouste Gulbenkian, 235-250.

E. Rabbie (2007), "Wit and Humor in Roman Rhetoric" in W. Dominik et J. Hall, eds. A Companion to Roman Rhetoric, Oxford, Blackwell, 2007, 207-217.

E. Rawson (2002), Intellectual life in the late Roman Republic, London, Duckworth.

J. Richardson (1994), "The administration of the empire" in J. A. Crook, A. Lintott et E. Rawson, eds. The Cambridge Ancient History, Vol. IX, Cambridge, Cambridge University Press, 564-598.

J. W. Roberts, ed. (2005), The Oxford Dictionary of the Classical World, Oxford, Oxford University Press.

R. Seager (1994), "The rise of Pompey" in J. A. Crook, A. Lintott, E. Rawson, eds. The Cambridge Ancient History, Vol. IX, Cambridge, New York, Cambridge University Press, 208-228.

C. Steel (2007), "Lost Orators of Rome" in J. Hall et W. J. Dominik, eds. A Companion to Roman Rhetoric, Oxford, Blackwell, 237-249.

W. Smith, ed. (1872), A Dictionary of Greek and Roman Biography and Mythology, London, John Murray, Albemarle Street.

P. Tansey (2010), "Antonia and the pirates", CQ 60/2, 656-658.

J. P. S. Valério (2014), A ascensão política de Marco António (49-44 a.C.). Dissertação de mestrado, Lisboa, Universidade de Lisboa.

K. E. Welch (1995), "Antony, Fulvia and the Ghost of Clodius in 47 B.C.”, G\&R, 42/2, 182-201.

J. Wisse (2002), "De Oratore: Rhetoric, Philosophy, and the making of the Ideal Orator" in J. M. May, ed. Brill's Companion to Cicero. Oratory and Rhetoric, Leiden, Brill, 375-400. 